\title{
Provenance Study of the Terracotta Army of Qin Shihuang's Mausoleum by Fuzzy Cluster Analysis
}

\author{
Rongwu $\mathrm{Li}^{1}$ and Guoxia $\mathrm{Li}^{2}$ \\ ${ }^{1}$ Department of Physics, Beijing Normal University, Beijing 100875, China \\ ${ }^{2}$ Faculty of Physical Engineering, Zhengzhou University, Zhengzhou 450052, China \\ Correspondence should be addressed to Rongwu Li; rongwuli@bnu.edu.cn
}

Received 29 August 2014; Revised 8 October 2014; Accepted 9 October 2014

Academic Editor: Ferdinando Di Martino

Copyright (c) 2015 R. Li and G. Li. This is an open access article distributed under the Creative Commons Attribution License, which permits unrestricted use, distribution, and reproduction in any medium, provided the original work is properly cited.

20 samples and 44 samples of terracotta warriors and horses from the 1st and 3rd pits of Qin Shihuang's Mausoleum, 20 samples of clay near Qin's Mausoleum, and 2 samples of Yaozhou porcelain bodies are obtained to determine the contents of 32 elements in each of them by neutron activation analysis (NAA). The NAA data are further analyzed using fuzzy cluster analysis to obtain the fuzzy cluster trend diagram. The analysis shows that the origins of the raw material of the terracotta warriors and horses from 1st and 3rd pits are not exactly the same but are closely related to the loam soil layer near Qin's Mausoleum while distant from the loess layers in the same area and remotely related to the Yaozhou porcelain bodies. It can be concluded that the raw material of the terracotta warriors and horses was taken from certain loam layer near Qin's Mausoleum and the kiln sites might be located nearby.

\section{Introduction}

The companion burial pits of terracotta army of Qin Shi Huang (the first emperor of China), which was begun to be built in $247 \mathrm{BC}$ and expanded nearly 40 years, were discovered in 1970s. Ever since then, they have been well known all over the world because of their long-standing history and their gigantic scale. There are over 7,000 life size terracotta warriors, chariots, and horses in these pits to guard Qin's Mausoleum. They are arranged in certain rules in three pits (numbered 1st, 2nd, and 3rd, resp.) to the east of Qin's Mausoleum. Experts name the 1st pit as Zhen (lineup), meaning troops charging forward. Experts name the 3 rd pit as $\mathrm{Mu}$ (curtain), meaning commanding post [1]. But where is the raw material of the terracotta warriors and horses taken from? Where are the kiln sites in which the terracotta warriors and horses were fired located? In order to solve these problems long puzzling archaeologists and scholars $[2,3]$, we use nuclear analysis technologies to study the origin of the raw material of the terracotta warriors and horses in Qin's Mausoleum in this paper.

The contents of microelements in the clay in an area are generally constant over extended period of time, and they are generally not affected by pottery production process. Therefore, the contents of microelement can be used as origin indicator for raw material of potteries. Many techniques, such as proton-induced X-ray emission (PIXE) or NAA, can be used to determine contents of microelements. These techniques have been used to study the origins of large amount ancient ceramics [4-8]. NAA technique has the advantage that it can determine contents of more than 30 elements of any given samples simultaneously. In this paper, we use NAA to determine the contents of 32 elements in each sample. The data are further analyzed using fuzzy cluster analysis. Such analysis reveals critical information about the raw material origins of Qin's terracotta warriors and horses.

\section{Measuring Methods and Results}

2.1. Samples. As listed in Table 1, nineteen terracotta warrior shards and one terracotta horse shard from the 1st pit and nine terracotta warrior shards and thirty-five terracotta horse shards from the 3 rd pit are selected as samples.

In order to study the relationship between Qin's terracotta warriors and the clay near Qin's Mausoleum, twenty soil samples are taken from different areas at different layers. 
TABLE 1: Samples of terracotta warriors and horses from the 1st and 3rd pits of Qin's Mausoleum.

\begin{tabular}{llr}
\hline Site & Sample code & Sample name \\
\hline \multirow{2}{*}{ 1st pit } & Q101 Q102 Q103 Q104 Q105 Q106 Q107 Q108 & Terracotta warrior shard \\
& Q109 & Terracotta horse shard \\
& Q110 Q111 Q112 Q113 Q114 Q115 Q116 Q117 Q118 Q119 Q120 & Terracotta warrior shard \\
\hline \multirow{3}{*}{ 3rd pit } & Q302 Q304 Q306 Q311 Q313 Q315 Q316 Q317 Q320 & Terracotta warrior shard \\
& Q325 Q326 Q327 Q328 Q329 Q330 Q331 Q332 Q333 Q334 Q335 Q336 & Terracotta horse shard \\
& Q337 Q338 Q339 Q340 Q341 Q342 Q343 Q344 Q345 Q346 Q347 Q348 & Terracotta horse shard \\
& Q350 Q358 Q362 Q364 Q368 Q370 Q371 Q373 Q374 Q377 Q379 & Terracotta horse shard \\
\hline
\end{tabular}

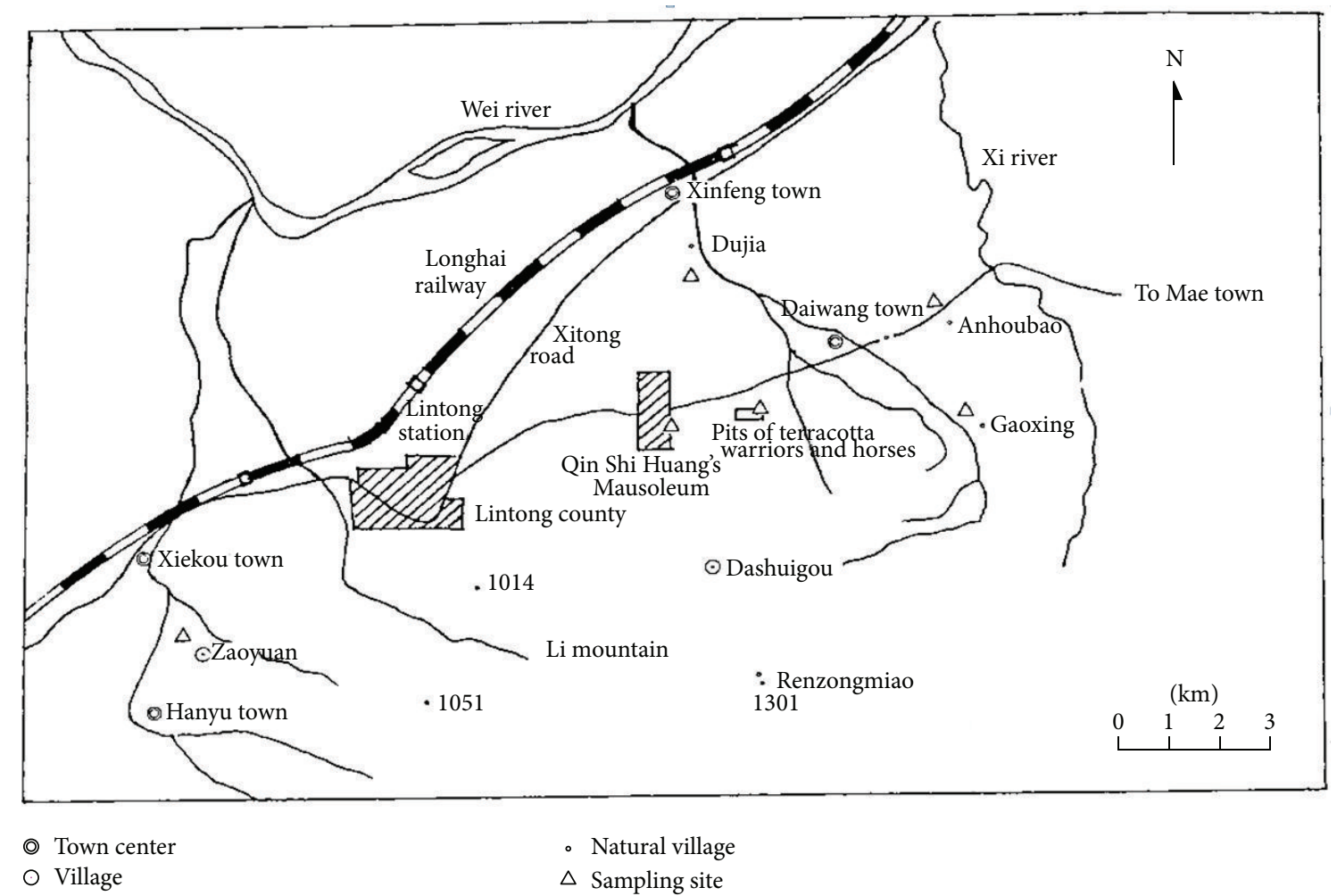

FIGURE 1: The map of sampling sites near Qin's Mausoleum.

The sampling areas are to the north of Lishan Hill and to the south of Wei River, within 10 KM range of Qin's Mausoleum. As shown in Figure 1, the sampling sites are located to the west, east, and north of Qin's Mausoleum. The other clay samples are taken from the sealing earth of Qin's Mausoleum and 2 nd pit. Table 2 lists all the samples taken. In addition, two samples (Y3b and Y6b) of Yaozhou porcelain bodies are also included as contrasting samples.

2.2. NAA Experiments and Results. In these experiments, the samples of terracotta warriors and the clays near Qin's Mausoleum are cut and grounded into fine powder and then oven-dried at $80^{\circ} \mathrm{C}$ for 8 hours. Each sample weighs $30 \mathrm{mg}$ and is wrapped with double-layered highly purified aluminum foil. In the meantime, 2 standard reference matter samples (code GBW07104 rock and code GBW07406 soil) are taken, $20 \mathrm{mg}$ each. All samples and standard reference matter are put into a radiation jar and irradiated for 8 hours in the heavy water reactor in the Institute of Chinese Atomic Energy Science. The neutron radiant flux is about $(3 \sim 7) \times$ $10^{13} \mathrm{n} \cdot \mathrm{cm}^{-2} \mathrm{~s}^{-1}$. The samples are measured for the $\gamma$-ray intensity for the first time by the highly pure germanium $\gamma$-ray spectrum instrument at the Institute of High Energy Physics of Chinese Academy of Science after being cooled for 7 days. They are measured again for the second time after being cooled for 15 days. 32 elements are identified in the samples and the content of each element is measured after comparing with that of the standard reference matters using neutron activation analysis program. The confidence level of the NAA data is $90 \%$ with its unit being $\mu \mathrm{g} / \mathrm{g}$. Among these elements, 9 are rare earth elements, namely, La, Ce, Nd, Sm, $\mathrm{Eu}, \mathrm{Tb}, \mathrm{Ho}, \mathrm{Yb}$, and $\mathrm{Lu}$, while the remaining elements are $\mathrm{Na}$, 
TABLE 2: The samples information of clay near Qin's Mausoleum.

\begin{tabular}{|c|c|c|c|c|c|}
\hline Sample code & Sample name & Sampling site & $\begin{array}{c}\text { Location and direction } \\
\text { with respect to Qin's } \\
\text { Mausoleum (KM) }\end{array}$ & $\begin{array}{l}\text { Depth beneath } \\
\text { earth }(\mathrm{M})\end{array}$ & $\begin{array}{c}\text { Characteristics } \\
\text { of the soil }\end{array}$ \\
\hline QL01 & $\begin{array}{l}\text { Sealing earth of } \\
\text { Qin's Mausoleum }\end{array}$ & Qin's Mausoleum & $\begin{array}{l}\text { Eastern part of Qin's } \\
\text { mausoleum }\end{array}$ & $4.0 \sim 5.0$ & Light earth yellow \\
\hline LZ01 & Loess & Zaoyuan, Lintong & West south, 9.5 & 5 & Light earth yellow \\
\hline LZ02 & Black loam & Zaoyuan, Lintong & West south, 9.5 & 6 & Dark yellow \\
\hline LZ03 & Red loam & Zaoyuan, Lintong & West south, 9.5 & 7 & Dark red \\
\hline LZ04 & Black loam & Zaoyuan, Lintong & West south, 9.5 & 8 & Same as LZ02 \\
\hline LZ05 & Loess & Zaoyuan, Lintong & West south, 9.5 & 10 & Light earth yellow \\
\hline LB01 & Black loam & Gaoxing, Lintong & East, 5.5 & 1 & Dark yellow \\
\hline LB02 & Loess & Gaoxing, Lintong & East, 5.5 & 2 & Light earth yellow \\
\hline LB03 & Black loam & Gaoxing, Lintong & East, 5.5 & 6 & Same as LZ02 \\
\hline LB04 & Red loam & Gaoxing, Lintong & East, 5.5 & 6.5 & Dark red \\
\hline LB05 & Loess & Gaoxing, Lintong & East, 5.5 & 10 & Light earth yellow \\
\hline LX01 & Black loam & Dujia, Lintong & North, 2.5 & 0.5 & Dark yellow \\
\hline LA01 & Black loam & Anhoubao, Lintong & East north, 5.0 & 1.5 & Dark yellow \\
\hline LA02 & Black loam & Anhoubao, Lintong & East north, 5.0 & 1.9 & Dark yellow \\
\hline LA03 & Black loam & Anhoubao, Lintong & East north, 5.0 & 2.5 & Dark yellow \\
\hline LA04 & Black loam & Anhoubao, Lintong & East north, 5.0 & 3.3 & Dark yellow \\
\hline QK21 & Backfill & 2nd pit & East, 1.5 & & \\
\hline QK22 & Tamping & 2nd pit & East, 1.5 & & \\
\hline QK23 & Black loam & 2nd pit & East, 1.5 & & \\
\hline QK24 & Loess & 2nd pit & East, 1.5 & & Light earth yellow \\
\hline
\end{tabular}

$\mathrm{K}, \mathrm{Ca}, \mathrm{Sc}, \mathrm{Cr}, \mathrm{Fe}, \mathrm{Co}, \mathrm{Ni}, \mathrm{Zn}, \mathrm{As}, \mathrm{Se}, \mathrm{Rb}, \mathrm{Sr}, \mathrm{Zr}, \mathrm{Mo}, \mathrm{Sb}, \mathrm{Cs}, \mathrm{Ba}$, Hf, Ta, W, Th, and U. Of all 32 elements, $\mathrm{Na}, \mathrm{K}, \mathrm{Ca}$, and Fe are common, and the remaining 28 are microelements.

2.3. Fuzzy Cluster Analysis Results. Cluster analysis is a generic term for a wide range of numerical methods for examining multivariate data with a view to uncovering or discovering groups or clusters of homogeneous observations. Clustering techniques have been employed in a remarkable number of different disciplines. In archaeology clustering has been used to investigate the relationship between various types of archaeological samples. In fuzzy clustering, objects are not assigned to a particular cluster: they possess a membership function indicating the strength of membership in all or some of the clusters. Memberships can be scaled to lie between 0 and 1 and can then be interpreted as probabilities. The fuzzy cluster analysis is based on fuzzy mathematics. It uses fuzzy matrix to define concepts, to discover rules, and to establish models. The NAA data of the 32 elements in the 86 samples are analyzed by fuzzy cluster analysis. Figure 2 is the trend fuzzy cluster analysis diagram. In this diagram, each sample belongs to a single cluster, and the complete set of clusters contains all samples. In some circumstances, however, overlapping clusters may provide a more acceptable solution. It should be noted that one acceptable answer from a cluster analysis is that no grouping of the data is justified. Based on the value of confidence level $\lambda$, the classification of the samples can be different. Nevertheless, each different classification based on different $\lambda$ is useful in the origin study. There is an optimum confidence level in every classification.

The basic data for cluster analysis is the usual $n \times$ $p$ multivariate (two-mode) data matrix, $X$, containing the variable values describing each object to be clustered; that is,

$$
X=\left[\begin{array}{cccc}
x_{11} & x_{12} & \cdots & x_{1 p} \\
x_{21} & \cdots & \cdots & \cdots \\
\vdots & \vdots & \vdots & \vdots \\
x_{n 1} & \cdots & \cdots & x_{n p}
\end{array}\right]
$$
$i$.

Entry $x_{i j}$ in $X$ gives the value of the $j$ th variable on object

Of central importance in attempting to identify clusters of observations which may be present in data is knowledge of how "close" individuals are to each other or how far apart they are. Two individuals are "close" when their dissimilarity or distance is small or their similarity is large. Proximities can be determined either directly or indirectly, and the latter is more common in most applications.

Indirect proximities are usually derived from the $n \times p$ multivariate (two-mode) matrix, $X$. There are a vast range of possible proximity measures.

In this study, when $\lambda$ is set to 0.886 , all samples are classified into 5 categories according to the trend fuzzy cluster analysis diagram as follows. 


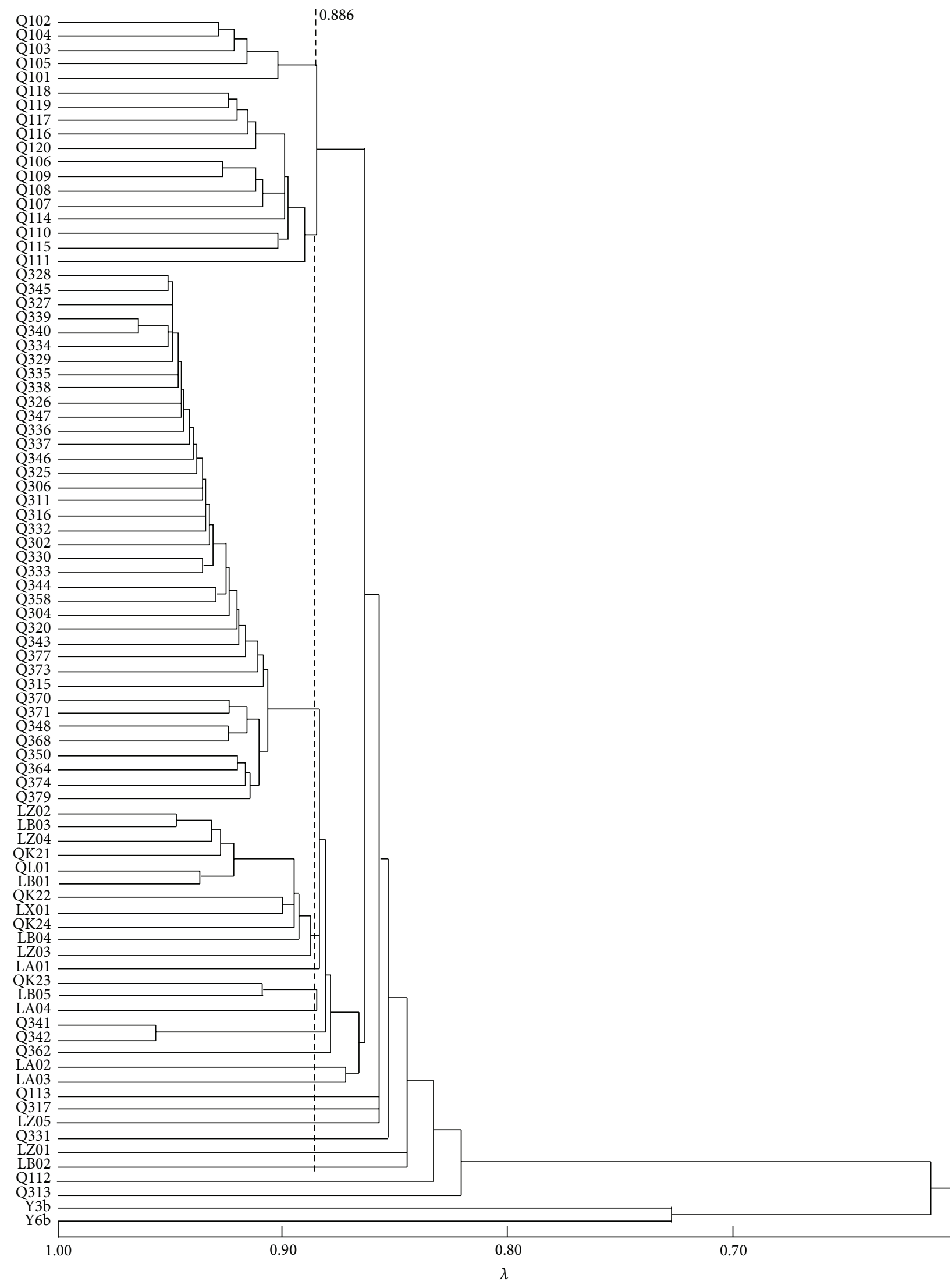

FIGURE 2: Trend fuzzy cluster analysis diagram for samples of terracotta warriors in Qin's Mausoleum 1st and 3rd pits and nearby clay. 
As shown in Figure 2, the 1st category (Q102 to Q111) includes 18 samples from 1st pit. Among them, Q102, Q104, Q103, and Q105 are more closely related as they can be classified into one category when $\lambda=0.915$. They are mostly shards of terracotta warrior's robes. Q118, Q119, Q117, Q116, and Q120 are more closely related as they can be classified into the same category when $\lambda=0.913$. They are all shards of terracotta warriors. The remaining 9 samples are not so closely related to them. This demonstrates that the raw material origins in the 1st pit are more diversified and the kilns for firing the terracotta warriors of the 1st pit might also be quite scattered around.

The 2nd category (Q328 to Q379) includes 38 samples. They include most samples from the $3 \mathrm{rd}$ pit. These samples are closely related which shows the origins of the raw material for the 3rd pit are quite concentrated and are quite independent of the 1st pit.

The 3rd category (LZ02 to LA01) includes 12 clay samples near Qin's Mausoleum. Among these samples, LZ02, LZ04 (the black loam $6 \mathrm{M}$ and $8 \mathrm{M}$ beneath the earth in Zaoyuan and Lingtong, resp.), LB01, LB03 (the black loam $1 \mathrm{M}$ and $6 \mathrm{M}$ beneath the earth in Gaoxing and Lingtong, resp.), QK21 (the backfill soil from the 2nd pit), and QL01 (the sealing earth of Qin's Mausoleum) are very closely related. These six samples can be classified into one category when $\lambda=$ 0.922. QL01, QK21, and QK22 (tamping earth) are regarded as the soil samples of the Qin or near Qin Dynasty. The samples that are closely related to them are black loam at various depths at Zaoyuan, Gaoxing, and Dujia in Lintong. This means the sealing earth of Qin's Mausoleum, the backfill earth, and tamping earth must be taken from these places or other places near Qin's Mausoleum where there are similar loam layers. In this category, QK24 is the only loess sample. It might have been contaminated either by nature causes or by human.

When $\lambda=0.884$, the 2 nd and 3 rd categories above can be merged into one category. This means most samples from the 3 rd pit are closely related to the loams from different depths at Zaoyuan, Gaoxing, and Dujia and the soil layer 1.5 meter under the earth at Anhoubao.

The 4th category (QK23 to Q313) includes 16 samples. When $\lambda=0.818$, the 16 samples fall into the same category. These samples include the loess of different depths from Zaoyuan and Gaoxing, the loam of different depths from Anhoubao, and some samples from pits number 1 and number 3 . This category is comparatively complicated and it virtually consists of 16 samples which are not closely related to one another. The loess layers could be regarded as the representative of this category.

All the samples above merged into one category when $\lambda$ was set to 0.821 .

Fifth category (Y3b, Y6b) includes 2 samples. They are all Yaozhou porcelain body samples. They are quite distant because they come from different kilns and have different mineral raw material origins. They are merged into one category when $\lambda=0.727$. They have no relation with the terracotta warriors and horses and the clays near Qin's Mausoleum.

\section{Conclusion}

We use fuzzy cluster analysis to analyze the NAA data for the 1st and 3rd pits of Qin's Mausoleum and nearby clay samples. Our study shows the following.

(i) The raw materials of the 1st pit are quite diversified. Therefore, the kilns for firing the terracotta warriors are quite scattered around.

(ii) The raw material origins of most 3rd pit terracotta warrior samples are very concentrated. The kilns for firing these terracotta warriors are limited to a small number of concentrated ones.

(iii) Samples from the 1st pit are relatively independent of those from the $3 \mathrm{rd}$ pit. The origins of their raw material are not exactly the same.

(iv) The samples from the 1st and 3rd pits are closely related to the loam samples near Qin's Mausoleum, while quite distant to loess samples near Qin's Mausoleum and very distant to Yaozhou porcelain body.

(v) The raw material for making terracotta warriors of the 1st and 3rd pits might be taken from loam layer at different depths at Zaoyuan, Gaoxing, Dujia, and Anhoubao in Lintong or another loam layer that has similar soil properties near Qin's Mausoleum. Their raw material origins should be places near Qin's Mausoleum. Therefore, the kilns for firing the terracotta warriors of the 1st and 3rd pits should be located near Qin's Mausoleum.

\section{Discussion}

NAA technology can be used to measure tens of elements in given samples. Fuzzy cluster analysis on NAA data can give clear, objective, and comprehensive results. As compared to other technologies, combing these two methods has unique advantage in studying raw material origins of ancient ceramics.

As reported by archeologists of Qin's Mausoleum terracotta warriors and horses, most of the parts of the terracotta warriors and horses were made from mold first and then glued together with clay paste, which was made of waterwashed clay and mixed with silver sand [9]. Nevertheless, the microelements contents of the terracotta warriors still preserve information about their origin. However, the samples in this study are taken from the shards of Qin terracotta warriors and horses. There is no information about which terracotta warriors and horses or which parts these samples belong to and the sample number is very limited. More samples are needed to enhance the confidence level of such analysis. It is very useful to set up an NAA database of Qin's terracotta warriors and nearby clay, with samples including different coded terracotta warriors and horses, as well as clay at different depths and places near Qin's Mausoleum. Such database can greatly enhance the research on the raw material origins of Qin's terracotta warriors, their firing kiln sites, and their craftsmanship. 


\section{Conflict of Interests}

The authors declare that there is no conflict of interests regarding the publication of this paper.

\section{Acknowledgments}

This work is supported by National Natural Science Foundation of China (51172212), Fundamental and Frontier Technology Research Projects in Henan province (102300410168), and Nuclear Analysis Technology Open Laboratory of Chinese Academy of Science (B0901).

\section{References}

[1] X. L. Wang, Focus Study on Qin's Mausoleum, San Qin Press, 1994, (Chinese).

[2] G. Q. Jin, X. J. Pan, and Z. T. Sun, Physical Archaeology, Shanghai Science \& Technology Press, 1989, (Chinese).

[3] J. Z. Li, Science and Technology History, Ceramics Volume, Beijing Science \& Technology Press, 1998 (Chinese).

[4] Z. Q. Zhang, H. S. Cheng, H. N. Xia, J. C. Jiang, M. H. Gao, and F. J. Yang, "Trace elements measurement by PIXE in the appraisal of the ancient potteries," Nuclear Instruments and Methods in Physics Research Section B: Beam Interactions with Materials and Atoms, vol. 190, no. 1-4, pp. 497-500, 2002.

[5] J. D. Robertson, H. Neff, and B. Higgins, "Microanalysis of ceramics with PIXE and LA-ICP-MS," Nuclear Instruments and Methods in Physics Research Section B: Beam Interactions with Materials and Atoms, vol. 189, no. 1-4, pp. 378-381, 2002.

[6] T. Calligaro, A. Mossmann, J.-P. Poirot, and G. Querré, "Provenance study of rubies from a Parthian statuette by PIXE analysis," Nuclear Instruments and Methods in Physics Research Section B, vol. 136-138, pp. 846-850, 1998.

[7] Z. Gao, J. Wang, S. Chen et al., "Provenance investigation on ancient Chinese Ru porcelains by neutron activation analysis," Atomic Energy Science and Technology, vol. 31, no. 4, pp. 360364, 1997 (Chinese).

[8] W. J. Zhao, Z. Y. Gao, and S. H. Chen, "Neutron activation analysis of the sources of raw material of porcelain made in official kilns in the Southern Song Dynasty," Archaeology, vol. 7, pp. 80-85, 1998 (Chinese).

[9] "The excavation team of the terracotta army of Qin's Mausoleum," Archaeo and Cultural Relics, vol. 3, pp. 108-119, 1980. 

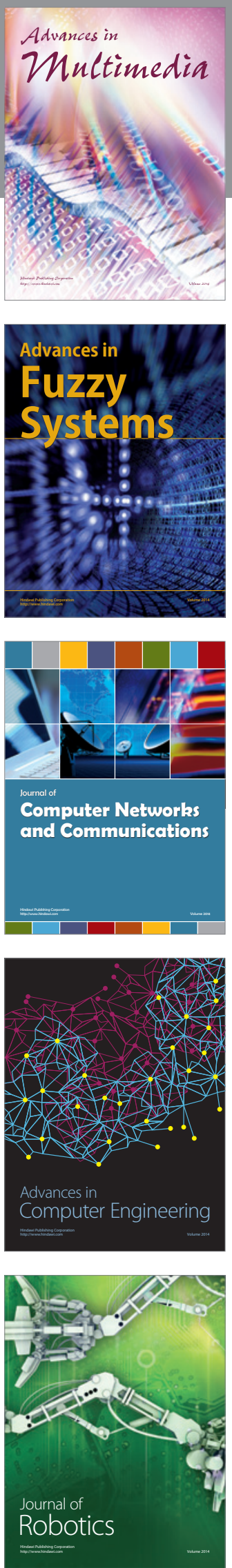

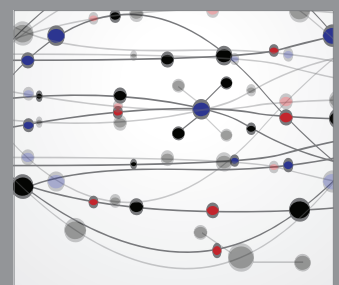

The Scientific World Journal
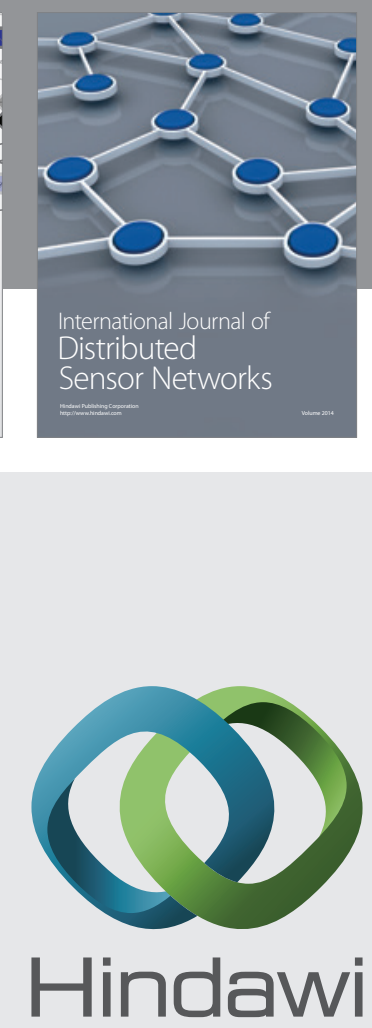

Submit your manuscripts at

http://www.hindawi.com
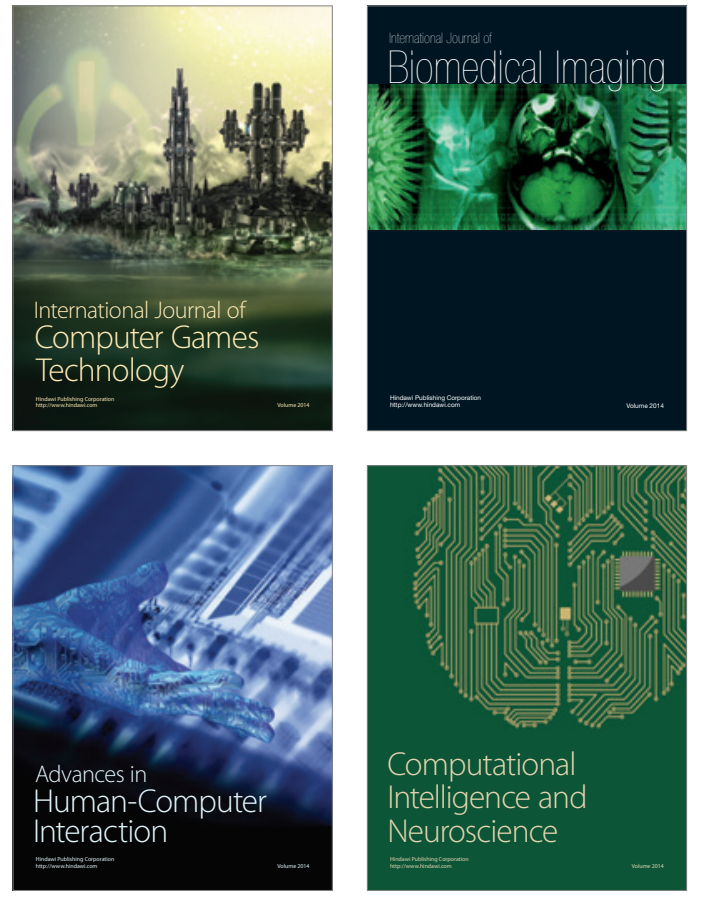
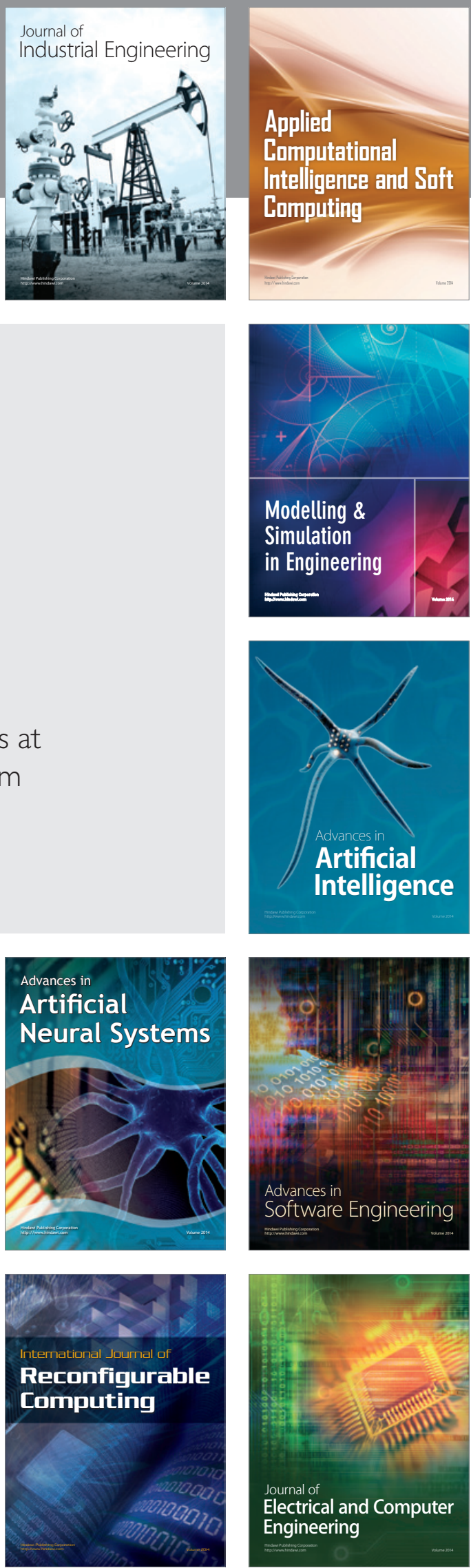